\title{
Effects of Home Exercise Program and Manual Therapy on Shoulder Function and Quality of Life in Patients with Adhesive Capsulitis
}

\author{
Kwang- II Kwak', Bum-Jin Choi ${ }^{2}$, Young-Jeoi Yoon ${ }^{3}$ \\ ${ }^{1}$ Rehabilitation center, Gwang ju plant, Kumho tire, Gwangju; ${ }^{2}$ Sport Rehabilitation center, Saenarae Hospital, Gwangju; ${ }^{3}$ Department of Physical \\ Therapy, Honam University, Gwangju, Korea
}

Purpose: This study was conducted to identify the effects of home exercise programs and manual therapy on shoulder function and quality of life in patients with adhesive capsulitis.

Methods: A total of 31 patients were enrolled in the study. All subjects were randomly assigned to a home exercise group $(n=15)$ or a manual therapy group $(n=16)$. Both groups performed each intervention program three times a week for four weeks. After four weeks, both groups performed a home exercise program continuously until week 12. Shoulder function was evaluated using the Korean Shoulder Scoring (KSS) system, while quality of life was evaluated using the WHO Quality of Life-BREF (WHOQOL-BREF) before and 4, 8, and 12 weeks after the intervention. Data were analyzed using two-way repeated measures analysis of variance (ANOVA).

Results: There were significant differences in KSS before intervention and 4, 8, and 12 weeks after intervention for both the home exercise group and manual therapy group $(p<0.001)$. There was also a significant difference in KSS at 4,8 , and 12 weeks when compared to the home exercise group and manual therapy group $(p<0.001)$. Moreover, there was a significant difference in WHOQOL-BREF before and 4,8 , and 12 weeks after intervention in the home exercise group and manual therapy group $(p<0.001)$.

Conclusion: Home exercise and manual therapy improved shoulder function, but manual therapy led to a greater improvement in shoulder function better than home exercise. Home exercise and manual therapy improved quality of life, but there was no significant difference between groups.

Keywords: Home exercise program, Manual therapy, Shoulder function, Quality of life, Adhesive capsulitis

\section{서 론}

견관절 유착성관절낭염(adhesive capsulitis)은 대부분 40-60세 이상의 중년 또는 노인 인구에 발생하는 견관절의 대표적인 질환으로 ${ }^{1}$ 많은 연구에도 불구하고 유착성관절낭염의 원인은 명확하게 밝혀지지 않 았으나, ${ }^{2,3}$ 활액막 아래층의 만성 염증으로 인한 관절막의 비후와 섬 유화, 관절막과 상완골 경부의 유착이 발생하여 통증이 서서히 증가 하고 점차적으로 능동 및 수동 관절운동범위가 감소하는 것으로 알 려져 있다. 45

견관절 통증은 관절가동범위의 감소와 상지의 움직임을 제한할 수 있으며, 이로 인하여 일상생활동작 수행의 어려움과 삶의 질이 감 소될 수 있다. ${ }^{6}$ 유착성관절낭염 환자의 견관절 관절가동범위 감소는
점진적인 기능 감소를 반영하며, 견관절 통증과 기능 장애는 삶의 질을 감소시킬 수 있다. 유착성관절낭염 환자는 심한 통증과 일상생 활의 기능 제한, 높은 수면 장애 발생률과 삶의 질이 낮으며, ${ }^{9}$ 유착성 관절낭염 환자의 견관절 기능 장애와 삶의 질 사이에는 음의 상관관 계(negative correlation)가 있다. ${ }^{10}$

유착성관절낭염의 치료는 통증을 감소시키고 관절의 운동성을 촉진하여 최대한의 운동범위를 회복하는 것을 목표로 하며," 도수치 료와 운동치료, ${ }^{12}$ 자가신장운동, ${ }^{7}$ 고유수용성 신경근 촉진법, ${ }^{1,14}$ 진동 자극, ${ }^{15}$ 그룹운동과 가정운동프로그램 ${ }^{16}$ 테이핑 요법 17 등의 물리치료 적 중재가 임상에서 널리 사용되고 있다. 유착성관절낭염 치료 방법 의 선택과 적용은 다양한 방식으로 진행되고 있으며, 통증 감소와 기 능 회복을 위해 도수치료 적용이 효과적이라고 보고되었다. 도수치 
료는 유착성관절낭염 환자의 통증 감소, 연부 조직과 관절낭의 뺏뻣 함을 신장시키며, ${ }^{18}$ 관절낭 내의 운동 저하와 기능적 움직임을 개선 하는 데 효과적이다. ${ }^{19}$ 가정운동프로그램은 경제적 제약이 적고 시설 과 공간의 제한 없이 쉽게 적용할 수 있는 운동으로 독립적인 일상생 활을 위한 간단한 프로그램으로 구성되어 있다. ${ }^{20}$ 치료사의 감독 하 에 시행되는 가정운동프로그램은 유착성관절낭염 환자의 통증과 장애를 개선시킬 수 있으며, ${ }^{21}$ 가정운동프로그램을 통하여 개인의 일 상생활 활동에 필요한 능력을 향상시킬 수 있다.22

유착성관절낭염 환자는 보존적 치료 후 비교적 양호한 결과를 얻 을 수 있으나 회복 후에도 부분적으로 관절 운동의 제한이 있을 수 있으며,23 통증과 관절 강직에 따른 기능 회복을 위해서는 상당한 시 간이 필요하다. ${ }^{16}$ 따라서 유착성관절낭염 환자의 치료를 위해서 장기 적인 치료적 중재가 필요하며, 보존적 치료 후 견관절 기능을 유지하 기 위한 적절한 중재가 필요한 것으로 생각된다. 또한 최근 질환의 평 가와 치료에 심리적, 사회적 요소가 포함된 삶의 질이 중요한 요소로 생각되고 있으나, 견관절 질환과 관련된 삶의 질에 대한 연구는 부족 한 실정이다. ${ }^{9}$

이에 본 연구는 4 주간의 도수치료와 가정운동프로그램 적용이 유 착성관절낭염 환자의 견관절 기능과 삶의 질에 미치는 영향을 확인하 며, 보존적 치료 후 5-12주까지의 가정운동프로그램 적용이 견관절 기능을 유지하기 위한 물리치료적 중재로써 유착성관절낭염 환자의 견관절 기능과 삶의 질에 미치는 영향에 대해 알아보고자 하였다.

\section{연구 방법}

\section{1. 연구대상}

본 연구는 기관생명윤리위원회(IRB No. 2014-12-019-003)의 심의를 거쳐 연구 승인을 받았으며, 모든 대상자들은 실험 절차와 주의사항 에 대해 충분한 설명을 들은 후 연구 참여 동의서에 자발적으로 서명 하였다. 본 연구의 대상자들은 J도의 관절전문병원에서 입원 및 외래 치료를 받고 있는 환자들을 대상으로 하였으며, Miller 등 ${ }^{4}$ 의 연구에 기초하여 방사선(X-ray) 검사 상 특이 소견이 없으며, 견관절 운동범 위 감소와 자연적으로 발생한 통증, 정상측 외회전 및 내회전 운동범 위의 $50 \%$ 미만 제한 등의 특징이 있는 사람을 유착성관절낭염 환자 로 선정하였다. 또한 유착성관절낭염의 초기 “통증 우세”에 해당하는 환자들을 최소화하기 위하여 최소 3 개월 이상 증상이 지속되는 환 자들을 대상으로 하였다. 지난 3 개월 동안 손상 측 어깨에 주사 치료 나 물리치료를 받은 사람, 손상 측 어깨의 회전근개 손상, 골절, 수술 을 받은 사람은 대상자 선정에서 제외시켰다. 모든 대상자들에게 약 물을 제외하고 실험 기간 동안 다른 보존적 치료를 받지 않도록 요청 하였으며, 일주일 이상 중재프로그램에 참여하지 못한 경우 실험에
서 제외하였다.

표본 크기는 검정력 및 표본 크기 산출 프로그램을 사용하였으며, 유의수준 $5 \%(\alpha=0.05)$, 검정력 $80 \%$ ( $\beta=0.80)$, 실험군과 대조군을 대상 으로 총 4 회 결과 값을 측정하였을 경우 교호작용을 볼 수 있는 전체 표본 수는 24 명이었다. 실험 과정에서 약 $10 \%$ 의 탈락률을 고려하여 대상자 수는 26 명으로 산출되었으며, 실험군과 대조군 각 13 명이 요 구되었다.

\section{2. 실험방법}

본 연구는 J도 관절전문병원에서 유착성 관절낭염으로 진단받은 환 자들을 대상으로 2015년 3월부터 5월까지 실험을 진행하였으며, 대 상자 선정 기준에 적합한 환자들을 무작위로 2 개의 그룹으로 할당하 였다.

첫 번째 군은 열, 전기치료를 포함한 기본 물리치료를 받았으며, 중 재 전 가정운동프로그램에 대한 교육을 실시하였다. 가정운동프로 그램은 유착성관절낭염에 대한 의학적 정보와 바람직한 생활습관, 통증 예방, 자가 운동 방법에 대한 교육을 실시한 후 책자를 제공하 였으며, 경부와 견관절 주변 근육에 대한 스트레칭, 도르래와 T-bar 운동 등이 포함된 자가 운동 방법을 교육하였다. 가정운동프로그램 은 어깨 재활운동 경력 5년 이상의 전문치료사가 운동 지도와 교육 을 담당하였으며, 기본물리치료를 받으러 병원에 내원하였을 때 가 정운동프로그램을 확인하였으며 잘못된 동작에 대해 재교육을 실 시하였다.

두 번째 군은 열, 전기치료를 포함하는 기본 물리치료와 도수치료 를 실시하였다. 도수치료는 10 년 이상의 임상 경험이 있는 정형도수 치료사가 전담하여 실시하였으며, 칼텐본-에반스 컨셉(KaltenbornEvjenth concept)을 기반으로 하였다. 기능적 마사지와 신장은 통증 감 소와 조직 이완을 위하여 극상근, 극하근, 소원근, 견갑하근, 대원근, 대흥근 및 상승모근 등에 적용하였다. 관절가동화기법은 각 환자 별 로 증상의 진행 경과에 따라 견관절 하방 및 후방활주, 외측 견인 등 을 실시하였으며, 흥추의 굴곡 및 신전 가동화운동을 실시하였다.

모든 중재는 하루 50 분, 일주일에 3 회, 총 4 주간 실시하였으며, 이후 부터 모든 군은 12 주까지 가정운동프로그램을 지속하도록 하였다. 중재 전과 중재 후 4 주, 8 주, 12 주에 견관절 기능과 삶의 질을 측정하 였다.

\section{3. 측정도구}

\section{1) Korean Shoulder Scoring (KSS) System}

KSS는 어깨 질환의 치료 전후 기능적 상태를 평가하는 데 국내에서 널리 이용되고 있으며, 다양한 어깨 질환의 평가에서 높은 신뢰도와 정확도를 나타내고 있다.25,26 평가 항목으로는 일상 활동을 평가하는 
기능 항목 30 점, 통증 20 점, 만족도 10 점, 관절운동범위 20 점, 도수 근 력 및 근지구력 항목 20점 만점으로 구성되어 있으며, 총 100점을 기 준으로 측정을 하며 점수가 높을수록 견관절의 기능적 상태가 좋음 을 의미한다. KSS의 Cronbach's $\alpha=0.840$ 이다. ${ }^{25}$

\section{2) WHO Quality of Life-BREF (WHOQOL-BREF)}

WHOQOL-BREF 는 세계보건기구에서 개발한 것을 국내에서 Min 등 $27(2000)$ 이 한국형 버전으로 축약한 것으로 신체적 건강, 심리적 건 강, 사회적 관계, 환경 영역 등에 속하는 24 개의 하부 척도와 전반적 인 삶의 질에 대한 2 개의 문항을 포함하여 총 26 개의 문항으로 구성 되어 있다. 각 문항의 점수는 5점 척도로 구성되어 있고, 총점을 100 점으로 환산하여 점수가 높을수록 건강관련 삶의 질이 좋음을 의미 한다. ${ }^{28} \mathrm{WHOQOL}-\mathrm{BREF}$ 는 WHOQOL 고유 척도의 간편형 척도로 높은 내적 일치도(internal consistency)와 검사-재검사 신뢰도(test-retest reliability)를 가지고 있어 대규모의 임상 연구에서 많이 활용되고 있다. ${ }^{28,29}$ 또한, 근골격계 질환을 가진 환자들을 대상으로 삶의 질을 측정하는 데 유용한 도구로 사용되고 있다.9,29,30

\section{4. 자료분석}

모든 자료는 SPSS PASW 18.0 windows을 이용하여 분석을 하였다. 정 규성 분포는 Shapiro-Wilk 검정을 실시하였으며, 대상자의 일반적 특 성은 $\chi^{2}$ 검정과 독립표본 $\mathrm{t}$ 검정(Independent t-test)을 실시하여 동질성 검증을 실시하였다. 가정운동프로그램과 도수치료에 따른 시간의 효과, 그룹 간의 비교, 시간과 그룹의 교호작용을 검증하기 위하여 반 복측정 이요인 분산분석(repeated measures two-way ANOVA)을 실시 하였다. 시간의 효과가 유의한 경우 중재 전과 측정 시기에 따른 차이 를 확인하기 위하여 대응표본 t 검정(paired t-test)을 실시하였으며, 시
간과 그룹의 교호작용이 유의한 경우 측정 시기에 따른 그룹 간차이 를 확인하기 위하여 독립표본 t 검정(Independent t-test)을 실시하였 다. 통계학적 유의 수준은 $\alpha=0.05$ 로 하였다.

\section{결 과}

\section{1. 연구 대상자들의 일반적 특성}

가정운동프로그램군은 15 명(남성 5 명, 여성 10 명)이었으며, 평균 연령 은 $53.73 \pm 4.68$ 세, 증상 지속기간은 $5.67 \pm 2.12$ 개월, 우세 팔에 $73.3 \%$ 가 이환되었다. 도수치료군은 16 명(남성 5 명, 여성 11 명)이었으며, 평균 연 령은 $51.06 \pm 6.45$ 세, 증상 지속기간은 $6.31 \pm 2.05$ 개월, 우세 팔에 $75 \%$ 가 이환되었다. 두 군의 성별 분포, 나이, 증상 지속기간, 우세 측 어깨 관 련 요인은 통계학적으로 유의한 차이가 없었다 $(\mathrm{p}>0.05)$ (Table 1).

\section{Korean Shoulder Scoring (KSS) System 결과}

견관절 기능적 상태를 평가하는 $\mathrm{KSS}$ 는 가정운동프로그램군에서 중 재 전 $45.4 \pm 8.43$ 점, 중재 후 4 주 $51.40 \pm 8.27$ 점, 중재 후 8 주 $57.60 \pm 8.03$ 점, 중재 후 12 주 $65.07 \pm 8.03$ 점이었으며, 도수치료군에서 중재 전 $44.56 \pm 8.21$ 점, 중재 후 4 주 $69.06 \pm 6.44$ 점, 중재 후 8 주 $76.56 \pm 4.62$ 점, 중 재 후 12 주 $80.38 \pm 5.81$ 점이었다. 측정 시기에 따른 유의한 차이가 있었 으며, 가정운동프로그램군과 도수치료군은 중재 전과 비교하여 중

Table 1. General characteristics of subjects

\begin{tabular}{lcc}
\hline & HE group $(\mathrm{n}=15)$ & MT group $(\mathrm{n}=16)$ \\
\hline Age (year) & $53.73 \pm 4.68$ & $51.06 \pm 6.45$ \\
Gender (M/F) & $5 / 10$ & $5 / 11$ \\
Duration of symptom (mo) & $55.1 \pm 10.3$ & $54.7 \pm 12.2$ \\
Side (dominant/nondominant) & $12 / 3$ & $12 / 4$ \\
\hline
\end{tabular}

HE: Home exercise, MT: Manual therapy.

Table 2. KSS score for each intervention group over time

\begin{tabular}{|c|c|c|c|c|c|c|c|}
\hline Group & Pre & 4 weeks & 8 weeks & 12 weeks & Time $(T)$ & Group (G) & $T \times G$ \\
\hline HE & $45.47 \pm 8.43$ & $51.40 \pm 8.27^{+}$ & $57.60 \pm 8.03^{+}$ & $65.07 \pm 8.03^{+}$ & $0.000^{\star \star \star}$ & $0.000^{\star \star \star *}$ & $0.000^{\star * \star}$ \\
\hline $\mathrm{MT}$ & $44.56 \pm 8.21$ & $69.06 \pm 6.44^{+, \neq}$ & $76.56 \pm 4.62^{+,+\neq}$ & $80.38 \pm 5.81^{+, \text {扞 }}$ & & & \\
\hline
\end{tabular}

Mean \pm S.D., ${ }^{* \star *} p<0.001$.

HE: Home exercise, MT: Manual therapy.

+Significantly different for pre intervention compared 4, 8, 12 weeks after intervention ( $p<0.001)$; *Significantly different for HE compared MT comparison at 4 weeks ( $p<0.001)$; ${ }^{*}$ Significantly different for HE compared MT comparison at 8 weeks $(p<0.001)$; ${ }^{* \neq}$ Significantly different for HE compared MT comparison at 12 weeks $(p<0.001)$.

Table 3. WHOQOL-BREF score for each intervention group over time

\begin{tabular}{lcccccc}
\hline Group & Pre & 4 weeks & 8 weeks & 12 weeks & Time (T) & Group (G) \\
\hline HE & $60.00 \pm 10.37$ & $68.07 \pm 7.58^{+}$ & $69.33 \pm 5.43^{+}$ & $72.80 \pm 4.46^{+}$ & $0.000^{\star \star \star}$ & 0.380 \\
MT & $58.81 \pm 8.56$ & $64.19 \pm 8.83^{+}$ & $66.50 \pm 8.02^{+}$ & $71.94 \pm 6.07^{+}$ & & \\
\hline
\end{tabular}

Mean \pm S.D., ${ }^{\star * *} p<0.001$.

HE: Home exercise, MT: Manual therapy.

+Significantly different for pre intervention compared 4, 8, 12 weeks after intervention $(p<0.001)$. 
재 후 4 주, 8 주, 12 주에 유의한 차이가 있었다 $(\mathrm{p}<0.001)$. 측정 시기와 그룹 간의 유의한 교호작용이 있었으며, 중재 후 4 주, 8 주, 12 주에서 가정운동프로그램군과 도수치료군의 유의한 차이가 있었다 $(\mathrm{p}<$ 0.001) (Table 2).

\section{WHOQOL-BREF score 결과}

삶의 질을 평가하는 WHOQOL-BREF는 가정운동프로그램군에서 중재 전 $60.00 \pm 10.37$ 점, 중재 후 4 주 $68.07 \pm 7.58$ 점, 중재 후 8 주 $69.33 \pm$ 5.43 점, 중재 후 12 주 $72.80 \pm 4.46$ 점이었으며, 도수치료군에서 중재 전 $58.81 \pm 8.56$ 점, 중재 후 4 주 $64.19 \pm 8.83$ 점, 중재 후 8 주 $66.50 \pm 8.02$ 점, 중 재 후 12 주 $71.94 \pm 6.07$ 점이었다. 측정 시기에 따른 유의한 차이가 있 었으며, 가정운동프로그램군과 도수치료군은 중재 전과 비교하여 중 재 후 4 주, 8 주, 12 주에 유의한 차이가 있었다 $(\mathrm{p}<0.001)$. 측정 시기와 그룹 간의 유의한 교호작용은 없었다( $\mathrm{p}>0.05)$ (Table 3).

\section{고 찰}

본 연구는 도수치료와 가정운동프로그램 적용이 유착성관절낭염 환자의 기능과 삶의 질에 미치는 영향을 확인하며, 보존적 치료 후 가 정운동프로그램 적용이 견관절 기능을 유지하기 위한 중재로써 유 착성관절낭염 환자의 견관절 기능과 삶의 질에 미치는 영향에 대해 알아보고자 하였다.

견관절의 기능적 상태를 평가하는 Korean Shoulder Scoring (KSS) System은 측정 시기에 따른 유의한 차이가 있었으며, 가정운동프로 그램군과 도수치료군은 중재 전과 비교하여 중재 후 4 주, 8 주, 12 주에 유의한 차이가 있었다 $(\mathrm{p}<0.001)$ 측정 시기와 그룹 간의 유의한 교호 작용이 있었으며, 중재 후 4 주, 8 주, 12 주에서 가정운동프로그램군과 도수치료군의 유의한 차이가 있었다 $(\mathrm{p}<0.001)$. O'Kane 등 ${ }^{31}$ 의 연구에 서 물리치료와 함께 실시된 간단한 가정운동프로그램은 유착성관 절낭염 환자의 견관절 기능 평가와 건강 상태를 개선하였으며, Miller 등 $^{24}$ 의 연구에서 기본 물리치료를 포함한 약물치료와 가정운동프로 그램을 병행하여 10 년 간 장기 추시한 결과 대상자들은 통증과 관절 가동범위의 제한없이 일상 활동에 복귀하였다. Seo와 $\operatorname{Shin}^{7}$ 은 자가신 장운동이 포함된 가정운동프로그램은 자기-제어적(self-control) 운동 으로써 장소와 시간의 제약이 적으며, 접근의 용이성과 지속적인 운 동을 통하여 근육불균형을 방지하고 질병의 진행을 예방할 수 있어 유착성관절낭염 치료에 대한 효과적인 중재방법으로 고려될 수 있다 고하였다.

$\mathrm{Ma}$ 등 32 의 연구에서 기본 물리치료와 도수치료 적용은 유착성관 절낭염 환자의 통증 감소, 관절가동범위 회복과 견관절 기능을 향상 시켰으며, Seo 등 ${ }^{33}$ 의 연구에서 치료사에 의해 적용된 관절가동운동
은 관절가동범위 증가와 통증을 감소시켰다. Mangus 등 34 은 관절가 동운동은 유착된 관절 조직의 유리화 및 관절낭 교원 섬유의 재배열, 연골 기질과 활액 사이의 흐름 증가를 통하여 관절의 움직임과 기능 을 회복시킨다고 하였다.

삶의 질을 평가하는 WHOQOL-BREF 점수는 측정 시기에 따른 유 의한 차이가 있었으며, 가정운동프로그램군과 도수치료군은 중재 전 과 비교하여 중재 후 4주, 8 주, 12 주에 유의한 차이가 있었다 $(\mathrm{p}<0.001)$. 측정 시기와 그룹 간의 유의한 교호작용은 없었다( $\mathrm{p}>0.05)$. Cho 등9의 연구에서 유착성관절낭염 환자의 WHOQOL-BREF 점수는 77.6점으 로 93.6점의 정상군과 비교해서 통계학적으로 유의하게 낮았으며, WHOQOL-BREF 하부 척도 점수도 전반적인 삶의 질과 신체적 건강 영역에서 정상군보다 낮게 나타났다. 또한 동통과 기능 정도를 평가 한 KSS 점수는 전반적인 삶의 질 및 신체적 건강과 양의 상관관계를 보였다. Cho 등 ${ }^{35}$ 의 연구에서 유착성관절낭염 환자의 통증은 일상 생 활의 어려움과 삶의 질을 저하시킬 수 있으며, Fernandes ${ }^{10}$ 의 연구에 서 유착성관절낭염 환자의 기능적 상태의 회복은 삶의 질 향상으로 이어질 수 있다고 하였다.

본 연구와 선행 연구의 결과 가정운동프로그램과 도수치료는 중 재 전과 비교하여 유착성관절낭염 환자의 견관절 기능을 유의하게 향상시켰으며, 본 연구의 결과 도수치료는 가정운동프로그램과 비교 하여 치료 후 4 주부터 빠른 기능적 상태의 회복을 보였으며 최종 12 주 추시 결과에서도 유의한 차이가 있었다. 가정운동프로그램과 도 수치료는 중재 전과 비교하여 유착성관절낭염 환자의 견관절 기능 을 향상시키지만 도수치료 적용이 유착성관절낭염 환자의 기능 향 상에 더욱 효과적인 중재방법으로 생각된다. 본 연구와 선행 연구의 결과 유착성관절낭염 환자에서 낮은 삶의 질을 확인할 수 있었으며, 본 연구의 결과 가정운동프로그램과 도수치료는 중재 전과 비교하 여 유착성관절낭염 환자의 삶의 질을 유의하게 향상시켰다. 유착성 관절낭염 환자의 삶의 질 향상은 가정운동프로그램과 도수치료 적 용 후 견관절 기능 향상에 따른 결과로 생각된다. 본 연구의 결과 견 관절 기능 회복은 가정운동프로그램과 도수치료에서 4 주, 8 주, 12 주 에 유의한 차이가 있었으나 삶의 질은 4 주, 8 주, 12 주에 유의한 차이 가 없었다. 도수치료에서의 삶의 질 향상은 견관절 기능 회복에 따른 결과로 생각되며, 가정운동프로그램에서의 삶의 질 향상은 견관절 기능 향상 외에 가정에서 치료를 통한 심리적, 사회적 요인이 작용한 것으로 생각된다. Bagheri 등 ${ }^{36}$ 은 유착성관절낭염 환자의 삶의 질은 통증, 기능 장애와 상당한 관련이 있지만 이차적으로 심리적인 요인 도 많은 영향을 미친다고 하였다. 4주간의 중재 후 지속적으로 실시 된 가정운동프로그램은 중재 전과 비교하여 8 주, 12 주에 유착성관절 낭염 환자의 견관절 기능과 삶의 질을 유의하게 향상시켰다. 이는 유 착성관절낭염 환자의 적절한 치료를 위해서는 장기적인 치료적 중재 
가 필요하며, 가정운동프로그램은 보존적 치료를 통한 기능 향상 후 유착성관절낭염 환자의 견관절 기능과 삶의 질 향상 및 유지를 위해 적용할수 있는 중재 방법으로 생각된다.

본 연구는 표본의 크기가 적고, 추시 기간이 짧아 연구의 결과를 일반화하는 데 어려움이 있으며, 가정운동프로그램과 도수치료의 중재자가 동일하지 않다는 제한점이 있다. 또한 가정운동프로그램과 도수치료 중재 후 견관절 기능과 삶의 질 향상을 확인하였으나 그에 따른 상관관계를 확인하지 못한 제한점이 있다. 앞으로의 연구는 본 연구의 제한점들을 보완하여 유착성관절낭염 치료를 위한 효과적인 중재 방법에 대한 다양한 연구가 필요한 것으로 생각된다.

\section{참고 문헌}

1. Green S, Buchbinder R, Hetrick S. Physiotherapy interventions for shoulder pain. Physiotherapy. 2003;89(6):335-6.

2. Hsu JE, Anakwenze OA, Warrender WJ et al. Current review of adhesive capsulitis. J Shoulder Elbow Surg. 2011;20(3):502-14.

3. Wong PL, Tan HC. A review on frozen shoulder. Singapore Med J. 2010; 51(9):694-7.

4. Bunker TD, Anthony PP. The pathology of frozen shoulder. A Dupuytren-like disease. J Bone Joint Surg Br. 1995;77(5):677-83.

5. Hannafin JA, DiCarlo EF, Wickiewicz TL et al. Adhesive capsulitis: capsular fibroplasia of the glenohumeral joint. J Shoulder Elbow Surg. 1994; 3(5):435-40.

6. Fotias F, Grouios G, Ypsilanti A et al. Hemiplegic shoulder syndrome: possible underlying neurophysiological mechanisms. Phys Ther Rev. 2005;10(1):51-8

7. Seo BD, Shin HS. The effect of self stretching exercise in patients with shoulder adhesive capsulitis. J Kor Phys Ther. 2010;22(1):19-26.

8. Gupta S, Raja K, Manikandan N. Impact of adhesive capsulitis on quality of life in elderly subjects with diabetes: A cross sectional study. Int J Diabetes Dev Ctries. 2008;28(4):125-9.

9. Cho CH, Jung SW, Son ES et al. Sleep status and quality of life in patients with frozen shoulder. J Korean Orthop Assoc. 2012;47(3):205-10.

10. Fernandes MR. Correlation between functional disability and quality of life in patients with adhesive capsulitis. Acta ortop bras. 2015;23(2):81-4.

11. Hamdan TA, Al-Essa KA. Manipulation under anaesthesia for the treatment of frozen shoulder. Int Orthop. 2003;27(2):107-9.

12. Page MJ, Green S, Kramer S et al. Manual therapy and exercise for adhesive capsulitis (frozen shoulder). Cochrane Database Syst Rev. 2014; 26(8):CD011275

13. Lim WS, Shin HS, Kim IS et al. The Effects of Scapular Pattern and Hold-Relax Technique of PNF on the ROM and VAS in Frozen Shoulder Patients. J Kor Phys Ther. 2002;14(1):15-26.

14. Kim SM, Lee HO, Bae SS. Effects on frozen shoulder as seen in the comparison hold-relax technique and rom exercise. J Kor Phys Ther. 1995; 7(1):51-9.

15. Choi WH, Lee JH, Min DK et al. The Effects of the Range of Motion of Joint with Vibratory Stimulation of the Patients of Adhesive Capsulitis of the Shoulder. The Journal of the Convergence on Culture Technology
(JCCT). 2015;1(2):77-83

16. Kwag KI, Seo EY, Kim TY. The effects of group exercise, manual therapy and home exercise on pain, range of motion and function in patient with adhesive capsulitis. J Kor Phys Ther. 2016;28(2):101-5.

17. Lee MH, Park RJ. The Effects of Taping Therapy on the ROM and VAS in Adhesive Capsulitis. J Kor Phys Ther. 2003;15(3):223-38.

18. Vermeulen HM, Rozing PM, Obermann WR et al. Comparison of highgrade mobilization techniques in the management of adhesive capsulitis of the shoulder: randomized controlled trial. Phys Ther. 2006;86(3)35568 .

19. Hyong IH, Ha MS. The effect of additional mobilization with conservative physical therapy in patients with frozen shoulder on rom and subjective pain scale. Journal of the Korea Contents Association. 2009;9(11): 271-9.

20. Jones GR, Frederick JA, Co-op BH. The Canadian centre for activity and aging's home support exercise program. Geriatrics and Aging. 2003; 6(7):48-9.

21. Carette S, Moffet H, Tardif J et al. Intraarticular corticosteroids, supervised physiotherapy, or a combination of the two in the treatment of adhesive capsulitis of the shoulder. Arthritis Rheum. 2003;48(3):829-38.

22. Outpatient ST. Therapy-based rehabilitation services for stroke patients at home. Cochrane Database Syst Rev. 2003;(1):CD002925.

23. Shaffer B, Tibone JE, Kerlan RK. Frozen shoulder. A long-term followup. J Bone Joint Surg Am. 1992;74(5):738-6.

24. Miller MD, Wirth MA, Rockwood CA. Thawing the frozen shoulder: the "patient" patient. Orthopedics. 1996;19(10):849-53.

25. Tae SK, Rhee YG, Park TS et al. The development and validation of an appraisal method for rotator cuff disorders: The Korean Shoulder Scoring System. J Shoulder Elbow Surg. 2009;18(5):689-96.

26. Kim DW, Sung JH, Jung JE et al. Correlation between shoulder scoring system and isokinetic muscle strength test. J Korean Orthop Soc Sports Med. 2010;9(2):104-8.

27. Min SK, Lee CI, Kim KI et al. Development of Korean version of WHO Quality of life scale abbreviated version (WHOQOL-BREF). J Korean Neuropsychiatr Assoc. 2000;39(3):571-9.

28. The WHOQOL Group. Development of the World Health Organization WHOQOL-BREF quality of life assessment. Psychol Med. 1998; 28(3):551-8.

29. Ackerman IN, Graves SE, Bennell KL et al. Evaluating quality of life in hip and knee replacement: psychometric properties of the World Health Organization Quality of Life short version instrument. Arthritis Rheum. 2006;55(4):583-90.

30. Koo HJ, Cho CH, Jung SW. Psychological status and quality of life in patients with rotator cuff disease. J Korean Soc Biol Ther Psychiatry. 2011; 17(1):96-103.

31. O'Kane JW, Jackins S, Sidles JA et al. Simple home program for frozen shoulder to improve patients' assessment of shoulder function and health status. J Am Board Fam Pract. 1999;12(4):270-7.

32. Ma SY, Je HD, Jeong JH et al. Effects of whole-body cryotherapy in the management of adhesive capsulitis of the shoulder. Arch Phys Med Rehabil. 2013;94(1):9-16.

33. Seo JH, Bae SS, Kim CY. The Effects of Glenohumeral Abduction Motion and Intra-articular Movement after Passive Caudal Gliding Mobilization in Frozen Shoulder Patients. J Kor Phys Ther. 2003;15(3):126-52. 
34. Mangus BC, Hoffman LA, Hoffman MA et al. Basic principles of extremity joint mobilization using a Kaltenborn approach. J Sport Rehabil. 2002;11(4):235-50.

35. Cho KH, Song JY, Lee H et al. The effect of subacromial bursa injection of hyaluronate in patients with adhesive capsulitis of shoulder joint: mul- ticenter, prospective Study. J Korean Acad Rehabil Med. 2002;26(1):7380.

36. Bagheri F, Ebrahimzadeh MH, Moradi A et al. Factors Associated with Pain, Disability and Quality of Life in Patients Suffering from Frozen Shoulder. Arch Bone Jt Surg. 2016;4(3):243-7. 